\title{
Why do business processes deviate? Results from a Delphi study
}

\author{
Ulrich Matthias König ${ }^{1}$ - Alexander Linhart ${ }^{2}$ • \\ Maximilian Röglinger ${ }^{3}$
}

Received: 7 December 2017/ Accepted: 11 September 2018/Published online: 28 September 2018

(C) The Author(s) 2018

\begin{abstract}
Despite substantial investments in business process management (BPM), every organization experiences deviant processes, i.e., processes that show different behavior than intended. Thus, process deviance is an essential topic of BPM research and practice. Today, research on process deviance is mainly driven from a computer science perspective. IT-based methods and tools (e.g., deviance mining and prediction or compliance checking) detect process deviance by comparing log data from past process instances with normative process models or execution traces of currently running instances. However, requiring process models and event logs as input, existing approaches are expensive and limited to processes executed in automated workflow environments. Further, they can only detect process deviance, not explain why it occurs. Thus, knowledge about reasons for process deviance is immature. What is missing is a systematic exploration of reasons for process
\end{abstract}

Electronic supplementary material The online version of this article (https://doi.org/10.1007/s40685018-0076-0) contains supplementary material, which is available to authorized users.

Maximilian Röglinger

maximilian.roeglinger@fim-rc.de

Ulrich Matthias König

ulrich.koenig@fim-rc.de

Alexander Linhart

alexander.linhart@fim-rc.de

1 Research Center Finance and Information Management, Project Group Business and Information Systems Engineering of the Fraunhofer FIT, University of Augsburg, Universitätsstraße12, 86159 Augsburg, Germany

2 Research Center Finance and Information Management, University of Augsburg, Universitätsstraße12, 86159 Augsburg, Germany

3 Research Center Finance and Information Management, Project Group Business and Information Systems Engineering of the Fraunhofer FIT, University of Bayreuth, Wittelsbacherring 10, 95444 Bayreuth, Germany 
deviance. Against this backdrop, we compiled and structured reasons for process deviance based on a rating-type Delphi study with more than 30 experts from industry and academia. Thereby, we chose a process manager's perspective as analytical lens, as process managers are familiar with and responsible for business processes end-to-end. We also analyzed the reasons' importance for causing deviance in routine and nonroutine processes, two process types that capture the nature of processes in terms of variation and variety. Our results contribute to the descriptive knowledge on process deviance and serve as foundation for prescriptive research.

Keywords Business process management $\cdot$ Process deviance $\cdot$ Delphi study

\section{Introduction}

Process orientation is an accepted paradigm of organizational design and a source of corporate performance (Kohlbacher and Reijers 2013; Recker and Mendling 2016). Today, many organizations adopt business process management (BPM) methods and tools to increase the effectiveness and efficiency of their processes and to comply with regulations (van der Aalst 2013; Alter 2015b). However, every organization experiences deviant processes, i.e., processes that show different behavior than intended, a phenomenon also known as process deviance (Weidlich et al. 2011; Depaire et al. 2013). Despite its ubiquity, knowledge on process deviance is in its infancy such that current discussion in the literature calls for further research (Rosemann 2014; Müllerleile et al. 2016; Mertens et al. 2016a; Delias 2017).

The literature on process deviance can be split into three groups. The first group aims to conceptualize process deviance and to classify related concepts, e.g., workarounds (Rinderle and Reichert 2006; Weber et al. 2006; Alter 2015a). The second group focuses on the detection (ex post view) and runtime prediction (ex nunc view) of process deviance. Powered by the rise of data-driven BPM methods and the adoption of process-aware information systems (IS), most approaches rely on process mining algorithms and data from process logs (Swinnen et al. 2012; Maggi et al. 2014; Nguyen et al. 2016; Delias 2017). They compare execution data of past process instances from process logs with normative process models and propose classifiers that indicate whether distinct process instances are deviant (Depaire et al. 2013; Nguyen et al. 2016). As for process deviance prediction at runtime, algorithms examine dependencies among exceptional situations, which may entail deviant behavior (Mourão and Antunes 2005; Weber et al. 2006; Mišic et al. 2010; Conforti et al. 2015). Despite the value of this contribution, existing approaches are expensive and restricted to business processes executed in automated workflow environments, as they require process models and logs as input (Nguyen et al. 2016). Due to their data-driven nature, existing approaches help detect and predict process deviance, but do not explain why it occurs (Depaire et al. 2013). Likewise, existing approaches are highly model centric and neglect 
important BPM context factors such as governance, people, and culture (Schmiedel et al. 2012; Depaire et al. 2013; vom Brocke and Rosemann 2015a; vom Brocke et al. 2016). Aiming to overcome the drawbacks of the second group, the third group focuses on the identification of reasons for process deviance (Andrade et al. 2016; Mertens et al. 2016b). With related work being domain or case specific, knowledge about reasons for process deviance requires further development (Andrade et al. 2016; Mertens et al. 2016a). What is missing is a systematic compilation of reasons for process deviance that complements the ex post and ex nunc view on process deviance currently dominating the literature. Thus, our research question is as follows: Why do business processes deviate?

To answer this research question, we split it into two operational questions: (1) What are reasons for process deviance? (2) How important are these reasons for causing process deviance in different contexts? We answered both questions by conducting a rating-type Delphi study with more than 30 international experts from academia and industry. The Delphi method is an accepted method in IS and BPM research, designed for exploratory consensus-seeking purposes such as issue identification, concept development, and prioritization (Schmidt 1997; Okoli and Pawlowski 2004; de Bruin and Rosemann 2007; Paré et al. 2013; Schmiedel et al. 2013; Becker et al. 2015). The exploratory and iterative nature of the Delphi method fits our research questions as the involved experts could benefit from the input of other experts, and they could think about reasons for process deviance as well as their importance multiple times (Okoli and Pawlowski 2004; Keeney et al. 2006).

In the brainstorming and narrowing-down phases of our Delphi study, we answered the first research question by identifying and structuring reasons for process deviance. As analytical lens, we chose the perspective of process managers. Though not being operationally involved in process execution, process managers are familiar with and responsible for business processes end-to-end both content-wise and regarding process performance. Thus, they play a key role in the coordination of work and the management of process deviance. For the same reason, process managers require neither process models nor $\operatorname{logs}$ to reason about whether a business process is deviant. This feature strengthens the ex ante view on process deviance and enables identifying broadly applicable reasons for process deviance. In the rating phase of our Delphi study, we addressed the second question by rating the identified reasons with respect to their importance for causing deviance in routine and nonroutine processes. The distinction between routine and nonroutine processes is common in organizational science, as both process types capture the nature of work in terms of variation and variety (Lillrank 2003), two concepts closely linked to process deviance. The distinction between routine and nonroutine processes is also relevant from an IS perspective, as the digital age, which is characterized by volatility, uncertainty, and complexity, and ambiguity (Bennett and Lemoine 2014), leads to a shift from routine to nonroutine processes (Gimpel et al. 2018). Between 60 and $80 \%$ of all processes are supposed to be nonroutine processes (Swenson 2010).

This study is organized as follows: in Sect. 2, we provide background information about BPM and process deviance. In Sect. 3, we outline and justify the research design of our Delphi study. In Sect. 4, we present and interpret our 
findings for both operational research questions. In Sect. 5, we discuss managerial and theoretical implications, before concluding in Sect. 6 by stating limitations and pointing to avenues for future research.

\section{Domain background}

\subsection{Business process management and process classifications}

BPM is the science and practice of overseeing how cross-functional work is performed in organizations to ensure consistent outcomes and to seize improvement opportunities (Dumas et al. 2018). BPM strives for two objectives, i.e., improving business processes and developing the BPM capability itself (Rosemann and vom Brocke 2015). From a lifecycle perspective, BPM comprises activities such as the identification, definition, modeling, implementation, execution, monitoring, controlling, improvement, and innovation of business processes (Dumas et al. 2018). Having all business processes of an organization in scope, BPM provides an infrastructure for effective and efficient work (Harmon 2016). Business processes, which are the central unit of analysis of BPM, include events, tasks, and decisions that involve process participants and resources to create valuable outcomes for customers (Dumas et al. 2018). Despite contrary empirical evidence, BPM research has long time been working on the tacit assumption that business processes can be specified exhaustively prior to execution in terms of process models and that they are executed as specified. Only recently business processes have been recognized as drifting information structures with partly emerging behavior that cannot be entirely controlled by process managers, a paradigm shift that further stimulated research on process deviance (Beverungen 2014).

In the literature, business processes are classified based on different criteria. The most common classification is that into core, support, and management processes, splitting business processes according to their role in corporate value creation (Armistead 1999; vom Brocke et al. 2016). Core processes are business processes whose customers are from outside the organization and willing to pay for products and services. Support processes ensure that core processes continue to function, whereas management processes plan, organize, communicate, monitor, and control corporate activities (Harmon 2016). Another popular classification, which stems from organizational science, focuses on how business processes deal with variation (i.e., deviance from objectives) and variety (i.e., the number of process variants) (Lillrank 2003). Accordingly, processes are split into standard, routine, and nonroutine processes. This classification is similar to Johnston et al. (2012) distinction between runner, repeater, and stranger processes, the difference being that Johnston et al. also account for volume (i.e., the number of executions). Encompassing a single variant with a defined input and output, standard processes are very simple. As combinations of standard processes, routine processes feature an arbitrary, but fixed number of variants that can be specified prior to execution via imperative process models, e.g., following the Business Process Model and Notation (BPMN) or Event-driven Process Chain (EPC) standards. Routine processes cover 
the predictable part of organizational behavior. In routine processes, the search for errors and solutions can proceed analytically and logically. In contrast, nonroutine processes deal with semi- or unstructured problems. They entail high uncertainty and degrees of freedom, covering the unpredictable and emerging part of organizational behavior. With the input and output of nonroutine processes being at least partially undefined, they cannot be exhaustively specified prior to execution in terms of imperative process models. If at all, this can be done via declarative process models or process flexibility strategies such as flexibility-by-underspecifiation (Schonenberg et al. 2008; di Ciccio et al. 2017). Due to their novelty, however, declarative process models are neither as mature nor as broadly used in industry as imperative process models. Importantly, although nonroutine processes are hard-to-capture via process models, they can show different behavior than intended, and thus be deviant. As the distinction between routine and nonroutine processes is more closely related to process deviance than the classification into core, support, and management processes, we adopted it as analytical lens to answer our second operational research question. Further, the distinction between routine and nonroutine processes is relevant from an IS perspective, as the digital age entails a shift from routine to nonroutine processes (Swenson 2010; Bennett and Lemoine 2014).

\subsection{Process deviance}

The BPM literature considers process deviance from various perspectives (Mertens et al. 2016b). It also discusses closely related concepts such as exceptions, workarounds, or non-compliant processes (Rinderle and Reichert 2006; Alter 2015a, b). Below, we look at deviance from an organizational psychology perspective, define process deviance for our purposes, and discuss related concepts.

In organizational psychology, Robinson and Bennett (1995) define deviant behavior as actions that differ from norms and damage an organization. Spreitzer and Sonenshein (2004) specify deviant behavior as behavior that intentionally differs from organizational norms. Compared to Robinson and Bennett (1995), they conceptualize deviance by abstracting from the negative effects typically associated with deviance. Thereby, they coined the term positive deviance as opposed to negative deviance. We critically reflect on the conceptual distinction between deviance and its effects in more detail below. Spreitzer and Sonenshein (2004) further distinguish between supra-conformity as well as a reactive, statistical, and normative approach to deviance. Supra-conformity, also referred to as excessive conformity, means that behavior is deviant if it exceeds boundaries deemed appropriate. The reactive approach means that behavior is deviant if it is criticized by a reference group. In line with the theory of variation, the statistical approach defines deviance as deviation from an expected average or another predefined value (Deming 1994). Finally, the normative approach defines deviance as deviation from accepted norms (Spreitzer and Sonenshein 2004).

Many ideas about deviant behavior from organizational psychology have been adopted in the context of process deviance (Müllerleile et al. 2015; Mertens et al. $2016 \mathrm{a}, \mathrm{b})$. When reviewing the literature, we found criteria that help define process 
deviance, which currently features no commonly accepted definition, for our purposes. These criteria are frequency, scope, and intention. Frequency captures whether deviant behavior occurs in one process instance, various or all process instances (Dumas and Maggi 2015). Scope covers whether deviant behavior occurs in individual tasks, sub-processes, or the entire process (Alter 2014). Finally, intention reflects whether deviant behavior occurs intentionally or unintentionally (Depaire et al. 2013; Mertens et al. 2016b). On this foundation, we propose and used the following definition of process deviance in line with our understanding that process deviance is an umbrella concept as illustrated below:

Process deviance indicates that a business process shows different behavior than intended. It may occur in individual tasks, sub-processes, or the entire process (scope). Process deviance may occur in one process instance, various or all process instances (frequency). Finally, it may also occur intentionally or unintentionally (intention).

Process deviance can affect process performance positively or negatively (Spreitzer and Sonenshein 2004; Alter 2014). Cases where process deviance positively influences process performance (e.g., less compliance violations, less volatility, or better average values of performance indicators) are referred to as positive or constructive process deviance, while cases associated with negative effects are called negative deviance (Chakraborty 2013; Dumas and Maggi 2015; Andrade et al. 2016; Delias 2017). As process deviance should not be mixed up with related performance effects, we discuss both concepts and its effects separately as far as possible.

The BPM literature discusses concepts such as exceptions, workarounds, and non-compliant processes. Admittedly, these concepts cannot be separated accurately as they stem from different research streams. However, we classify them using the criteria from above to provide clarity as far as possible (Table 1). Exceptions are interruptions of tasks or process executions due to expected or unexpected events (Eder and Liebhart 1998; Mišic et al. 2010). Exceptions typically occur in one instance or various instances as well as in individual tasks or sub-processes. Further, they occur mostly unintentionally. Exceptions occurring in all process instances are referred to as errors. Captured and handled appropriately, exceptions enable runtime

Table 1 Classification of concepts related to process deviance

\begin{tabular}{|c|c|c|c|c|c|c|c|c|}
\hline & \multicolumn{3}{|c|}{ Frequency } & \multicolumn{3}{|c|}{ Scope } & \multicolumn{2}{|c|}{ Intention } \\
\hline & $\mathrm{O}$ & $\mathrm{V}$ & A & $\mathrm{T}$ & $\mathrm{S}$ & $\mathrm{P}$ & $\mathrm{U}$ & I \\
\hline $\begin{array}{l}\text { Exceptions (not properly } \\
\text { handled) }\end{array}$ & $\mathrm{X}$ & $\mathrm{X}$ & & $\mathrm{X}$ & $\mathrm{X}$ & & $\mathrm{X}$ & \\
\hline Workarounds & $\mathrm{X}$ & $X$ & $\mathrm{X}$ & $\mathrm{X}$ & $\mathrm{X}$ & & & $\mathrm{X}$ \\
\hline Non-compliant processes & $\mathrm{X}$ & $\mathrm{X}$ & $\mathrm{X}$ & $\mathrm{X}$ & $\mathrm{X}$ & $\mathrm{X}$ & $\mathrm{X}$ & $\mathrm{X}$ \\
\hline
\end{tabular}

Frequency: one instance (O), various instances (V), all instances (A)

Scope: individual tasks $(\mathrm{T})$, sub-processes $(\mathrm{S})$, entire process $(\mathrm{P})$

Intention: unintentional (U), intentional (I) 
flexibility and avoid process deviance (Simon and Mendling 2006). Otherwise, they reflect different behavior than intended. Workarounds are intentional and goalorientated adaptations, improvisations, or best practices in work systems that relate to single tasks or sub-processes (Alter 2014). They can be seen as responses to barriers during process execution (Röder et al. 2014). Workarounds can occur once, sometimes, and always. Finally, process compliance generally requires business processes to be executed in conformance with predefined specifications (e.g., process models, business rules, or external regulations) (Ferneley and Sobreperez 2006; Weidlich et al. 2010; Becker et al. 2011; Alter 2015b). Non-compliant processes violate such specifications. Non-compliant processes can occur once, sometimes, and always as well as intentionally and unintentionally (Alter 2015b). Non-compliance can also occur in individual tasks, sub-processes, or the entire process. Concluding, the term non-compliance is conceptually very similar to process deviance and can be used synonymously. Exceptions have a more technical background and workarounds have been introduced from a work systems perspective. They represent special forms of process deviance.

\section{Research design}

\subsection{General information about Delphi studies}

To answer our operational research questions, we conducted a Delphi study with international experts from industry and academia. Exploratory in nature, Delphi studies strive for consensus on a specific topic among a group of experts (Dalkey and Helmer 1963; Keeney et al. 2006). Thereby, experts provide their opinions on the topic in focus and comment on the opinions of other experts throughout multiple rounds (Dalkey and Helmer 1963). Our Delphi study strived for identifying and structuring reasons for process deviance from a process manager's perspective. It also investigated the identified reasons' importance for causing deviance in routine and nonroutine processes (Lillrank 2003).

In recent years, guidelines and rigor criteria for Delphi studies have been proposed (Okoli and Pawlowski 2004; Keeney et al. 2006; Paré et al. 2013; Skinner et al. 2015). We accounted for this knowledge and elaborate on this in the next sections. In line with Dalkey and Helmer (1963), Delphi studies include panelists, ensure end-to-end anonymity, reach consensus iteratively via several rounds, and incorporate the panelists' feedback in a structured manner. Panelists are experts who provide their opinion and comment on the opinion of other experts (Okoli and Pawlowski 2004). Experts can be organized in one or more panels. Ensuring anonymity is essential to avoid bias as, for instance, panelists with a self-confident appearance may influence other panelists (Okoli and Pawlowski 2004; Skinner et al. 2015). In addition, Delphi studies take multiple rounds to capitalize on the creativity and expertise of all panelists. In each round, the panelists should be provided with structured feedback such that they can trace progress and assess whether their input has been reasonably integrated into the overall position of the panel. Panelists should also be allowed to change their opinion and to provide feedback on both 
(intermediate) results and the study at large. Thereby, it is vital that panelists are not forced to adjust their previous responses (Paré et al. 2013).

The exploratory and iterative nature of the Delphi method fits our research questions. As knowledge on reasons for process deviance is immature, an exploratory research method is appropriate (Andrade et al. 2016). Further, an iterative method enables experts to benefit from the feedback of other experts and to think about reasons for process deviance as well as their importance repeatedly (Okoli and Pawlowski 2004). Thus, we preferred the Delphi method over other methods such as exploratory interviews where experts are involved only once and sequentially. The perspective of process managers, which we chose in our Delphi study for the reasons outlined in the introduction, can be suitably addressed by the Delphi method (Paré et al. 2013). This is because experienced experts from industry and academia can put themselves in the position of process managers and judge reasons for process deviance accordingly. However, in case process deviance is studied from complementary perspectives (e.g., the perspective of process participants), other research methods (e.g., observations, interviews, or ethnographies) are more suitable. As we will discuss in the conclusion, confirmatory research methods (e.g., surveys) are most appropriate to validate the results of our exploratory Delphi study.

\subsection{Structure of our Delphi study}

To structure our Delphi study, we followed the blueprint of ranking-type Delphi studies as proposed by Schmidt (1997), which is the most commonly used Delphi blueprint in IS research (Paré et al. 2013). Correspondingly, our study included three phases: brainstorming, narrowing down, and rating. As we did not rank, but rate reasons for process deviance with respect to their importance for causing process deviance in the third phase, we refer to our study as a rating-type Delphi study. While the brainstorming and narrowing down phases helped answer the first operational research question, the rating phase covered the second research question. We preferred rating (i.e., the assignment of reasons to predefined ordinally scaled importance categories) over ranking (i.e., the assignment of reasons to ordered ranks in line with their importance), as we were interested in the reasons' importance for causing deviance in routine and nonroutine processes as well as in potential differences between routine and nonroutine processes. We were not interested in the reasons' relative importance for causing deviance compared to one another for either process type (Keeney et al. 2006). The rating of reasons enables multiple reasons to be assigned to the same rating category. Further, ranking is only feasible for a small number of items. However, restricting our results to a few reasons for process deviance would not have done justice to the multi-faceted nature of business processes. Table 2 provides an end-to-end perspective on our Delphi study with all relevant statistics, which we explain below.

In the brainstorming phase, we collected an initial list of reasons for process deviance (round 1), created an initial and aggregated coding, and asked the panelists to comment on the resulting medium list (round 2). We also proposed categories for structuring the reasons. In the narrowing down phase, each panelist had to select the 
Table 2 Overview of the Delphi study procedure and statistics

\begin{tabular}{lllllll}
\hline Phase & \multicolumn{2}{l}{ Brainstorming } & Narrowing down & \multicolumn{2}{l}{ Rating } & \\
\hline Round & 1 & 2 & 3 & 4 & 5 & 6 \\
Active panelists & 29 & 27 & 33 & 27 & 22 & 25 \\
$\quad$ Academics & 13 & 14 & 17 & 15 & 13 & 14 \\
Practitioners & 16 & 13 & 16 & 12 & 9 & 11 \\
Number of reasons $^{\mathrm{a}}$ & 91 & 61 & 33 & 33 & 33 & 33 \\
Satisfaction study overall (mean) $^{\mathrm{b}}$ & - & - & 5.73 & 5.81 & 6.05 & 6.08 \\
Satisfaction study overall (SD) $^{\mathrm{b}}$ & - & - & 0.62 & 0.67 & 0.71 & 0.63 \\
Satisfaction coding (mean) $^{\mathrm{c}}$ & - & 5.63 & 5.73 & 5.78 & - & - \\
Satisfaction coding (SD) $^{\mathrm{c}}$ & - & 0.73 & 0.75 & 0.74 & - & - \\
\hline
\end{tabular}

${ }^{\mathrm{a}}$ After coding or voting

${ }^{\mathrm{b}}$ Likert scale from 1 to 7 (not assessed before round 3)

${ }^{c}$ Likert scale from 1 to 7 (only assessed until round 4, reflects the satisfaction with the coding results of the previous round)

most important reasons from his or her perspective, independent from specific contexts (round 3). On this foundation, we compiled a shortlist of reasons for process deviance. In the rating phase, the shortlisted reasons were rated regarding their importance for causing deviance in routine and nonroutine processes (rounds 4-6). Whereas the number of Delphi rounds is predetermined for the brainstorming and narrowing down phases (i.e., two and one rounds, respectively), it depends on three termination conditions in the rating phase (Paré et al. 2013). The rating phase terminates if consensus has been reached among the panelists (Okoli and Pawlowski 2004), if the expert assessment does not change significantly between subsequent rounds, or after at least three rounds so as not to overstrain the panelists. It is sufficient that one of these termination rules holds true (Paré et al. 2013).

In our Delphi study, we conducted six rounds. The panelists had 1 week per round to provide their answers, either per email or an online questionnaire. In each round, the panelists could provide open-ended feedback, and we provided them with their input from the previous round, a summary of relevant changes, and detailed instructions. We asked for the panelists' satisfaction with the study (overall satisfaction) as well as with the presented reasons and categories (coding satisfaction), using a Likert scale ranging from 1 (fully unsatisfied), 2 (strongly unsatisfied), 3 (unsatisfied), 4 (neutral), 5 (satisfied), and 6 (strongly satisfied) to 7 (fully satisfied) (Schmiedel et al. 2013).

\subsection{Selection of panelists}

Panelists should be motivated and have great expertise (Delbecq et al. 1975; Keeney et al. 2006). To recruit and manage experienced panelists, we prepared a knowledge resource nomination worksheet that captures selection criteria (Okoli and 
Pawlowski 2004). To ensure a broad view on BPM and process deviance, we included panelists from academia and industry as recommended and common practice (Okoli and Pawlowski 2004). We used the following selection criteria: Panelists from academia had to be specialized in BPM and at least hold a PhD. These criteria ensure that involved academic panelists had great domain expertise and a broad overview, which enabled them to complement the experience of experts from industry (Okoli and Pawlowski 2004). Grounded on their research activities, some academic experts also had valuable insights into the BPM practices of several organizations. Industry panelists had to hold a key role in their organization's BPM function or in BPM consulting, and they should have at least 5 years of work experience (Okoli and Pawlowski 2004; Schmiedel et al. 2013). This ensures that they are familiar with the perspective of process owners. To identify panelists, we used our industrial and academic networks. We also invited authors from vom Brocke and Rosemann's 'Handbook on Business Process Management' (vom Brocke and Rosemann 2015a, b), recognized for its comprehensive view on BPM (Schmiedel et al. 2013).

To identify the most suitable experts for our Delphi study, all prospective panelists were ranked according to the derived selection criteria (Okoli and Pawlowski 2004; Keeney et al. 2006). Overall, we invited 120 experts from 11 countries. These experts were asked to nominate further experts (Okoli and Pawlowski 2004). In the beginning, 40 experts committed themselves to participate in our study. This corresponds to a response rate of $33 \%$. Due to no shows and dropouts, between 22 and 33 panelists participated in the single rounds. This amounts to an initial no show ratio of $27.5 \%$ and a fraction of involved panelists between 82.5 and $66.7 \%$ (Table 1). The size of our panel complies with the guidance available for Delphi studies (Paré et al. 2013). With business processes and process deviance being multi-faceted phenomena, a large panel size also fit the domain in focus. The participating panelists were physically distributed with a geographical focus on Germany, the US, and Australia. All panelists met the selection criteria. Almost all panelists from industry even exceeded our requirements, having more than 10 years of work experience and holding leadership roles. Please have a look at Appendix A-1 for more information about our panel.

\subsection{Pilot study}

As recommended, we conducted a pilot study to ensure an appropriate study design (Skinner et al. 2015). The pilot study was done with test panelists that met the same requirements as for the main study. To offset potential bias, we excluded the test panelists from the main study. When preparing the pilot study, we identified two ways for setting up the brainstorming phase. The first option was a greenfield approach where reasons for process deviance were collected, providing the panelists without additional information (Schmidt 1997). The second option was to provide the panelists with an established framework to structure their brainstorming efforts (Kasiri et al. 2011). For this purpose, we identified Rosemann and vom Brocke's (2015) BPM capability framework as suitable, as it is well known and takes a holistic broad perspective on BPM (Kerpedzhiev et al. 2016; Schmiedel et al. 2013). 
Although Rosemann and vom Brocke's framework focuses on an organization's BPM capability, its core elements (i.e., strategic alignment, governance, methods, IT, culture, and people) also apply to individual processes, if the 'methods' core element is re-conceptualized as 'process design'.

In the pilot study, we prepared a questionnaire for both options. In the first questionnaire, the test panelists were asked to name and briefly describe at least fifteen reasons for process deviance. In the second questionnaire, the test panelists had to provide five reasons per core element of the BPM capability framework. Groups of three and two test panelists used the first and second questionnaires, respectively. The test panelists who used the first questionnaire were unable to list fifteen reasons, starting to repeat reasons after about ten items. The panelists who used the second questionnaire experienced problems in applying the framework. One industry panelist could not answer the second questionnaire as he was unfamiliar with the framework, a situation we would have been unable to avoid in the main study. In line with these results, we decided to design the brainstorming phase as a greenfield approach. Further, we asked each panelist to name only between six and ten reasons in the brainstorming phase to focus on the most important reasons for process deviance (Schmidt et al. 2001).

\subsection{Brainstorming phase}

In the first brainstorming round, we provided the panelists with a description of the end-to-end structure of our Delphi study as well as with detailed definitions and instructions. In line with the results of the pilot study, the panelists had to name between six and ten reasons why processes show different behavior than intended (Schmidt et al. 2001; Okoli and Pawlowski 2004). To support the subsequent coding and consolidation, we also asked the panelists to provide a short description per reason. We also used the first questionnaire to gather further information about the panelists and to confirm that they meet the selection criteria. In this round, all panelists received identical questionnaires (Okoli and Pawlowski 2004). We received 192 responses from 29 panelists.

To consolidate the panelists' individual input into an integrated position of the panel, we coded all responses using iterative coding (Schmidt 1997; Okoli and Pawlowski 2004; Krippendorff 2013). Before that, one co-author anonymized all responses. Thus, the panelists were anonymous not only for one another, but also for the research team. As recommended by existing Delphi guidelines, the other coauthors first coded the panelists' responses independently (Paré et al. 2013). We initially identified identical reasons and merged explanations (Schmidt et al. 2001; Okoli and Pawlowski 2004). We then identified categories and merged reasons with similar descriptions (Delbecq et al. 1975; Schmidt et al. 2001; Okoli and Pawlowski 2004; Paré et al. 2013). In a final workshop series, all co-authors discussed and consolidated their individual coding results. All reasons were formulated in a domain-agnostic manner and with a positive polarity, meaning that reasons point to process deviance if they can be confirmed. After this initial coding, we had 91 reasons and 9 categories. 
To validate these results, we performed a second brainstorming round (Schmidt et al. 2001; Keeney et al. 2006). This time, we asked the panelists to provide feedback on each reason and category. To provide the panelists with sufficient guidance, we presented them their input from the first round. To avoid bias, we implemented a randomized questionnaire, i.e., the order of categories and reasons per category were randomized (Paré et al. 2013). The panelists were also allowed to name new reasons based on their own or ideas and those of other panelists. We sent the questionnaire to 39 panelists, as 1 expert withdrew in the first round, and 27 panelists provided feedback. We distributed the questionnaire to all panelists who had initially agreed to participate in our study to leverage as much creativity and expertise as possible. As the average coding satisfaction was 5.63 on the seven-point Likert scale, the panelists were almost strongly satisfied with the consolidated reasons and categories (Table 1). Again, all co-authors evaluated the panelists' anonymized feedback independently and then consolidated their individual evaluations. Not to get biased by individual panelists, reasons or categories were only changed or deleted if this was suggested by several panelists. Reasons were added, if they were not included in any existing reason. Importantly, our intention was not to keep the number of reasons for process deviance small in this round, as this was the objective of the narrowing down phase. Finally, we reached an agreement on 61 reasons on the medium list, structured into ten categories.

\subsection{Narrowing down phase}

The narrowing down phase consisted of one round, aiming to identify the most important reasons for process deviance. Another purpose is to reduce the number of reasons to a manageable number. We asked the panelists to select those reasons that are both in accordance with their individual expert judgement and independent from distinct contexts (i.e., routine and nonroutine processes), most important for causing process deviance (Schmidt 1997). As typical for Delphi studies, we did not provide the experts with a formal definition of importance, but left the assessment up to their judgement. Each panelist had to select 20 reasons, as this number has been recognized as manageable and comprehensive in previous Delphi studies (Schmidt 1997). The idea behind narrowing down is that only reasons that exceed a minimum number of votes remain on the shortlist used as input for the rating phase (Schmidt 1997; Paré et al. 2013). In contrast to some other Delphi studies, we decided not to split the panel into an academic and an industry panel. We did so as we were interested in commonalities and differences between routine and nonroutine processes in terms of the reasons' importance, which we analyzed in the rating phase, instead of commonalities and differences regarding the judgement of academics and practitioners. If we had split the overall panel into academics and practitioners, we also would have run the risk that the final panels became too small.

The randomized questionnaire of round three was distributed to 39 panelists. Analogous to the second round, we invited all initially committed panelists, as panelists did not require specific knowledge from prior rounds to select the most important reasons. In this round, 33 panelists provided feedback. The satisfaction with the coding and the panelists' overall satisfaction with the study increased to 
5.73 (Table 1). Based on the panelists' responses, we shortlisted all reasons voted for by at least ten panelists, i.e., 30\% of the panel (Paré et al. 2013). We shared this cut-off criterion and let it approve by the panelists. On this foundation, 34 reasons remained on the shortlist. One reason voted for by ten panelists (i.e., exactly the threshold) received qualitative comments about redundancies with another reason and was dropped after a discussion within the author team. Further, we dropped one category ('IT changes') as all related reasons received too few votes.

Consequently, the narrowing-down phase resulted in a shortlist of 33 reasons structured along nine categories. As we did not only identify reasons for process deviance, but also structured them into categories, the results of the narrowing down phase comply with other Delphi guidelines, which recommend the number of shortlisted items not to exceed 30 (Paré et al. 2013). Further, the reasons and categories answer our first operational research question, which strived for identifying and structuring reasons for process deviance independent from specific contexts.

\subsection{Rating phase}

The rating phase sought to answer our second operational research question, asking how important the identified reasons are for causing process deviance in different contexts. To do so, we let the experts rate all shortlisted reasons regarding their importance for causing deviance in routine and nonroutine processes (Schmidt 1997). The panelists had to indicate the reasons' importance for both process types separately using the following ordinal scale: A (extremely important), B (very important), C (important), and D (unimportant). Just like in the narrowing down phase, we did not provide the experts with a definition of importance. As the rating phase included several rounds where panelists were confronted with their own rating as well as the aggregated rating distribution of the panel, the experts' individual understanding of 'important' was calibrated throughout these rounds. We chose the mentioned ordinal scale to seamlessly connect to the narrowing-down phase, which resulted in a shortlist of generally important reasons for process deviance independent from specific contexts. Thus, the first three rating categories related to different degrees of importance. We included rating category D (unimportant) for cross-checking purposes because it may have been the case that individual panelists wanted to assess reasons as unimportant for causing process deviance in either routine or nonroutine processes. As can be seen in Table 3, this was indeed the case, but very seldom. If this circumstance had occurred often, we would have had to go back to the narrowing down phase. Further, if we had not included rating category $\mathrm{D}$, the panelists would not have been able to declare reasons as unimportant, a circumstance that would have biased our rating results. We informed the panelists that rating category D was only included for crosschecking purposes, ensuring that they did not perceive the rating scale as nonequidistant. As outlined in Sect. 3.1, the key advantage of a rating of reasons is that multiple reasons can be assigned to the same rating category and that larger items sets can be handled. 
Table 3 Shortlisted reasons for process deviance

\begin{tabular}{|c|c|c|c|c|c|c|c|}
\hline The Process Itself & $\mathbf{R}$ & NR & $\begin{array}{c}\mathbf{R} \\
\text { Median }\end{array}$ & $\begin{array}{c}R \\
\text { Modus }\end{array}$ & $\begin{array}{c}\text { NR } \\
\text { Median }\end{array}$ & $\begin{array}{c}\text { NR } \\
\text { Modus }\end{array}$ & $\begin{array}{c}\mathrm{p}- \\
\text { value }\end{array}$ \\
\hline The process deals inappropriately with different contexts.** & 且 & n-e & B & B & A & A & 0.00020 \\
\hline The process is unable to cope with unexpected events. & n & $n=$ & A & A & A & A & 0.69800 \\
\hline The process includes inappropriate tasks.*** & 要 & $-n$ & A & A & c & c & 0.00000 \\
\hline The process includes an inappropriate control flow:*** & E= & -1 & A & A & c & $\mathrm{C}$ & 0.00000 \\
\hline \multicolumn{8}{|l|}{ Process Documentation } \\
\hline The process documentation is hard to access and/or not clearly communicated.* & - & 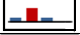 & B & B & в & B & 0.00187 \\
\hline The process documentation was created without consulting relevant process participants and stakeholders.* & 世. & $\underline{n=0}$ & A & A & A & A & 0.00118 \\
\hline The process documentation is missing or incomplete.* & ne & $+=$ & A & A & A & A & 0.00128 \\
\hline \multicolumn{8}{|l|}{ Process Change } \\
\hline The process is infrequently checked for up-to-dateness. & En & 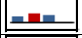 & B & A & в & в & 0.13886 \\
\hline The process was designed without consulting relevant process participants and stakeholders. ${ }^{* *}$ & 世 & 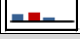 & A & A & в & B & 0.00009 \\
\hline \multicolumn{8}{|l|}{ Customer } \\
\hline Customers impose unexpected requirements on the process. & ne & 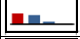 & A & A & в & A & 0.86187 \\
\hline Customers change their requirements while the process is being executed. & 且 & $\underline{n=-1}$ & в & в & в & A & 0.09299 \\
\hline \multicolumn{8}{|l|}{ Knowledge and Skills of Process Participants } \\
\hline Process participants do not have relevant knowledge and/or skills.*** & 咀 & + & A & A & A & A & 0.00067 \\
\hline Process participants do not have sufficient routine in executing the process.* & 且 & 咀 & B & в & в & B & 0.00154 \\
\hline Process participants do not know how their work contributes to the overall process outcome.* & $=$ & 且些- & $\mathrm{C}$ & $\mathrm{C}$ & в & A & 0.00181 \\
\hline Process participants are unaware of escalation strategies for dealing with unexpected events. & 旦 & 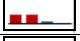 & в & A & в & $\mathrm{A}, \mathrm{B}$ & 0.94622 \\
\hline Process participants are unaware of their roles and responsibilities. & 咀 & 且是 & B & A & A & A & 0.14742 \\
\hline \multicolumn{8}{|l|}{ Attitudes and Behavior of Process Participants } \\
\hline Process participants do not identify themselves with the objectives of the process.*** & 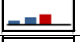 & مب & $\mathrm{C}$ & c & в & A & 0.00000 \\
\hline Process participants are unmotivated. *** & - & 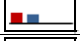 & c & $\mathrm{B}, \mathrm{C}$ & B & A & 0.00000 \\
\hline Process participants tend to change the process by themselves. ${ }^{* * *}$ & 且 & 世 & в & A & A & A & 0.00000 \\
\hline Process participants are often interrupted at work. & - & 年 & $\mathrm{C}$ & в & $\mathrm{C}$ & $\mathrm{C}$ & 0.19284 \\
\hline Process participants do not communicate with one another and/or the process owner if needed. & בn & 量 & в & B & в & в & 0.28489 \\
\hline \multicolumn{8}{|l|}{ Resources (i.e., material, equipment, employees) } \\
\hline Resources tend to be temporarily or systematically unavailable.**** & 咀 & 㥀 & A & A & в & A & 0.00000 \\
\hline The process competes with other processes for scarce resources. & - & |l一e & в & в & в & B & 0.61405 \\
\hline Resources do not scale with varying workload. & 且 & - & B & в & B & B & 0.29867 \\
\hline \multicolumn{8}{|l|}{ Governance and Strategic Alignment } \\
\hline The process has no defined process owner.*** & & 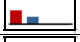 & в & в & A & A & 0.00000 \\
\hline The process owner is equipped with insufficient authority.** & 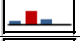 & 是 & в & B & в & A & 0.00062 \\
\hline Roles and responsibilities within the process are missing or specified ambiguously.**** & ne & 旦 & A & A & B & A & 0.00000 \\
\hline Stakeholders have unrealistic expectations regarding process performance. & 要 & | & c & $\mathrm{C}$ & в & в & 0.39642 \\
\hline \multicolumn{8}{|l|}{ IT in Use } \\
\hline Required data is scattered over multiple sources. & $-\ln$ & $\underline{\underline{n}}$ & B & в & в & B & 0.69817 \\
\hline Relevant IT systems do not provide the required functionality. & 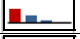 & En & A & A & A & A & 0.76584 \\
\hline Relevant IT systems have unnecessarily complex user interfaces. & 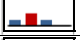 & - & в & в & в & B & 0,19873 \\
\hline The process requires many and/or non-integrated IT systems to be used. & - & -1 & в & в & в & $\mathrm{C}$ & 0.08129 \\
\hline Process participants do not have access to relevant IT systems and/or data. & $n=$ & بــ & в & в & B & A & 0.97908 \\
\hline
\end{tabular}


The questionnaire of round four was distributed to those 33 panelists who participated in the narrowing down phase. We decided to invite only those panelists who had at least participated in the third round to avoid discussions about the shortlisted reasons in a late and structured Delphi phase, not designed to account for qualitative feedback on the identified reasons. Thereby, we ensured that all panelists were familiar with the identified reasons and categories and had approved the shortlist. The questionnaire included the shortlisted reasons, definitions, and examples of routine and nonroutine processes as provided by Lillrank (2003), as well as a description of the rating scale. In this round, 27 panelists provided feedback. The overall satisfaction and the coding satisfaction, which we collected for the last time in this round, increased to 5.81 and 5.78, respectively (Table 1). This coding satisfaction needs to be attributed to the shortlist of reasons, as the panelists were confronted with the entire shortlist in this round the first time. As the coding satisfaction was very close to strongly satisfied and had continuously increased during the previous rounds, we considered this as content-wise consensus regarding the shortlist of reasons for process deviance. That is, the shortlist has been approved by the panelists and constituted a solid foundation for the rating phase.

As a constitutive characteristic, rating-type Delphi studies do not only strive for content-wise consensus of shortlisted items in the narrowing down phase. Rather, in the rating phase, they also strive for quantitative consensus in terms of stable rating distributions regarding the shortlisted items' importance for different contexts (Paré et al. 2013). However, as the Delphi method is exploratory in nature, the quantitative results of the rating phase should be interpreted as trend statements. They should be validated through both further exploratory (e.g., semi-structured interviews) and confirmatory research methods (e.g., surveys). We get back to this need for future research in the discussion.

To support the quantitative assessment of the rating distributions' stability, we applied Kendall's $W$, an accepted consensus measure typically applied in rankingtype Delphi studies (Schmidt 1997). In line with the nature of the Delphi method, even the rating phase must not be terminated only based on quantitative criteria. Rather, the termination decision should also account for qualitative insights such as provided by the panelists' feedback. It is important to note that we used Kendall's $W$ for measuring changes in consensus, not for measuring absolute consensus. We did so by comparing the Kendall's $W$ values for subsequent rounds. The reason is that we did not rank the identified reasons in relation to one another, but rated them individually. However, Kendall's W only measures absolute consensus for rankings. Looking at changes in consensus is reasonable when striving for consensus in terms of stable rating distributions at the end of a Delphi study, i.e., minor changes in the rating results of two subsequent rounds (von der Gracht 2012). In round four, Kendall's $W$ was 0.08 and 0.06 for routine and nonroutine processes.

The questionnaire of the fifth round included the shortlist of reasons for process deviance as well as the aggregated rating distributions of the fourth round in terms of bar charts highlighting the rating category (modus) that received the most votes (Table 3). We also repeated the definitions and examples of routine and nonroutine processes to remind the panelists of the characteristics of these process types. In addition, we provided each panelist with his or her individual rating from the 
previous round (Schmidt 1997; Paré et al. 2013). We informed the panelists that they can but need not adjust their prior voting. In this round, 22 panelists provided feedback. The overall satisfaction increased to 6.05, i.e., the panelists were strongly satisfied (Table 1). Kendall's $W$ doubled to 0.15 and 0.22 for routine and nonroutine processes, respectively. Due to this substantial change compared to the previous round, we performed a sixth round.

In round six, the panelists received the same questionnaire as in round five, with updated information. In this round, 25 panelists provided feedback. The panelists continued to be strongly satisfied, with an overall satisfaction of 6.08 (Table 1). Taking a value of 0.20 , Kendall's $W$ increased only slightly for routine processes. With a value of 0.21 , Kendall's $W$ slightly decreased for nonroutine processes. As the rating distributions changed only slightly between the fifth and the sixth rounds and as we had already conducted three rating rounds, we terminated our Delphi study in line with accepted termination conditions (Paré et al. 2013). Further, the panelists' satisfaction continuously increased during the study and reached the highest value in this round. Complementing these quantitative assessments, the panelists' qualitative feedback corroborated that the results had converged. In sum, the results reflect stable rating distributions per reason and process type. These results answer our second research question.

After the sixth round, we checked whether the differences and commonalities regarding the reasons' importance for routine and nonroutine processes were statistically significant. To do so, we used the $G$ test, as it is geared to small sample sizes (Holmes et al. 2011). The $G$ test checks the rating distributions of routine and nonroutine processes for homogeneity. Significance means that both distributions most likely stem from heterogeneous populations. Although the size of our panel fitted the exploratory nature of Delphi studies, it is rather small for statistical purposes. Thus, as mentioned above, the differences in importance for routine and nonroutine processes should be seen as trend statements whose underlying causality needs to be substantiated in future research. We get back to this limitation in the conclusion. This in mind, we investigated commonalities and differences regarding the reasons' importance for causing deviance in routine and nonroutine processes, because digitalization leads to a shift between both process types and because related insights indicate how process deviance needs to be managed. In our opinion, these insights complement the rating distributions and stimulate future research.

Finally, we checked for selection bias to ensure that satisfaction values had not risen because dissatisfied experts dropped out and only satisfied experts remained, but rather because the remaining panelists had become more satisfied during the study. This was important as the satisfaction values continuously increased during the study (Table 1). To that end, we looked at the final satisfaction values for all panelists who dropped out. An overall satisfaction of 5.56 and a coding satisfaction of 5.44 before dropout suggest that panelists did not drop out due to dissatisfaction and that our results do not suffer from selection bias.

Please refer to Appendix A-2 for detailed information about the medium list of reasons including the fraction of votes, votes from academics and practitioners, and ranking differences. The final rating distributions for the shortlisted reasons 
obtained in the rating phase are included in Appendix A-3. More information about the panelists' satisfaction values can be found in Appendix A-4.

\section{Results}

Our Delphi study yielded high satisfaction with the identified reasons and categories as well as stable rating distributions regarding the reasons' importance for causing deviance in routine and nonroutine processes. As an answer to our first operational research question, we compiled a shortlist of 33 reasons for process deviance from a process manager's perspective. These reasons are independent from distinct contexts and were structured into the following nine categories: the process itself, process documentation, customer, knowledge and skills of process participants, attitudes and behavior of process participants, resources, governance and strategic alignment as well as IT in use. To answer the second research question, we analyzed how important the identified reasons are for causing deviance in both process types. On this foundation, we also looked at commonalities and differences for both process types.

Table 3 summarizes the results for both research questions. It includes the shortlisted reasons and categories, their rating distributions, medians and modi as well as the $p$ values and significance codes. Below, we present our results in detail structured along the identified categories. When discussing commonalities and differences regarding the reasons' importance, we used the median as primary criterion (von der Gracht 2012). In case of different medians, we used the modus and $G$ test statistics to check whether the difference is significant. To keep this section focused, we interpret commonalities and differences using the properties of routine and nonroutine processes as analytical lens, which we introduced in Sect. 2. While the discussion in this section deliberately stays very close to the content of Table 3, we take a broader perspective on theoretical and managerial implications in Sect. 5 .

The category 'the process itself' includes four reasons. With one exception, these reasons are differently important for routine and nonroutine processes. The reason that a process deals inappropriately with different contexts is very important for routine processes and extremely important for nonroutine processes. Thereby, process contexts indicate in which environments a process is executed (Ghattas et al. 2014; Reichert et al. 2015). This finding seems plausible as nonroutine processes tend to be executed at least partly in unpredictable contexts, whereas the contexts of routine processes are prespecified and constant. Thus, nonroutine processes show different behavior than intend if they cannot cope with unpredictable contexts. The reason that a process is unable to cope with unexpected events is extremely important for routine and nonroutine processes. In our opinion, this makes sense as routine processes strongly depend on appropriate exception handling to ensure high pace and precision. At the same time, the unpredictability of nonroutine processes makes the handling of unexpected events one of their key challenges. The reason that a process includes inappropriate tasks is extremely important for routine processes and important for nonroutine processes. The same 
holds for an inappropriate control flow. We think that both findings are reasonable as inappropriate tasks and control flows substantially interfere with the desired pace and precision of routine processes. As for nonroutine processes, which are at least partly characterized by emerging behavior, tasks and control flows must be set up individually and managed in an ad hoc manner.

The 'process documentation' category includes three reasons, all of which are equally important for routine and nonroutine processes. The reason that the process documentation is hard to access and/or not clearly communicated is very important. In contrast, the reasons that the process documentation was created without consulting relevant process participants and stakeholders as well as that the process documentation is missing or incomplete are extremely important. In our opinion, these findings appear sensible as routine and nonroutine require high-quality process documentation, but for different reasons. Routine processes require documentation to train process participants. Thus, documentation is a vital source of efficient routine processes (Ungan 2006). However, routine processes may not require an overly deep documentation on the task level as they are typically executed very often such that process participants have substantial routine. As for nonroutine processes, it is impossible to compile end-to-end documentations at design time. Instead, high detail is needed on the task level as some tasks may be executed very seldom. Moreover, a comprehensive documentation of efficiency and effectiveness objectives is important to characterize desired outcomes of nonroutine processes.

The category 'process change' encompasses two reasons that complement both previous categories from a dynamics-oriented perspective. The reason that a process is infrequently checked for up-to-dateness is very important for routine and nonroutine processes. In contrast, the reason that a process has been designed without having consulted relevant process participants and stakeholders is extremely important for routine and very important for nonroutine processes. In our opinion, this seems plausible as nonroutine processes are set up ad hoc such that process participants and stakeholders are involved more frequently anyway. In contrast, routine processes require an extensive involvement of process participants and stakeholders prior to execution such that pace and precision can be achieved at runtime.

The fourth category focuses on customers as a special group of process participants or stakeholders who receive or co-create the process output (Dumas et al. 2018). Customers can be from outside (core processes) or inside an organization (support processes). When analyzing the medians of the reason that customers impose unexpected requirements on the process is extremely important for routine processes and very important for nonroutine processes. However, this difference is neither backed by the modi of both rating distributions nor by the test statistics. Thus, this result needs further examination in future research. Customers who change their requirements while a process is being executed are very important for routine and nonroutine processes. On the one hand, one might have expected a higher importance of this reason for routine processes, as it is key for nonroutine processes to deal with volatile contexts. On the other hand, this finding complies with our insights from the category 'the process itself' where the inability to deal with unexpected events (changes of customer requirements during runtime can be 
interpreted rather as unexpected events than as unpredictable contexts) has been rated as equally important for routine and nonroutine processes.

The category 'knowledge and skills of process participants' comprises five reasons. Three reasons are equally important for routine and nonroutine processes, one reason is differently important, and another reason cannot be unambiguously assessed. The reason that process participants do not have relevant knowledge or skills is extremely important for routine and nonroutine processes. Process participants who do not exhibit sufficient routine in executing a process are very important for routine and nonroutine processes. Moreover, knowledge about escalation strategies for dealing with unexpected events is very important. The reason that process participants do not know how their work contributes to the overall process outcome is very important for nonroutine processes and important for routine processes. In our opinion, this difference is plausible as participants of nonroutine processes can cope with unpredictability by knowing how their work contributes to the overall process outcome. In routine processes, process participants tend to be specialized in distinct tasks. Further, high division of labor ensures high pace and precision. Thus, knowledge about the contribution of one's work to the overall outcome is less important than in nonroutine processes. Finally, the reason that process participants are unaware of their roles and responsibilities is extremely important for nonroutine processes. In contrast, it is very important with a strong tendency to extreme importance for routine processes. However, this difference is neither backed by the modi of the rating distributions nor by the test statistics.

The 'attitude and behavior of process participants' category is closely related to the previous category. It includes five reasons, whereof three are differently important for routine and nonroutine processes. The reason that process participants do not identify themselves with the objectives of a process is important for routine processes and very important nonroutine processes. The same holds for the reason that process participants are unmotivated. We think that these findings make sense as, in uncertain contexts with volatile process inputs, process participants need to be highly motivated and identify themselves with the process objectives to go 'the last mile' when solving customer problems. These findings also comply with the results from the 'knowledge and skills' category regarding process participants' knowledge on how their work contributes to the overall process outcome. The reason that process participants tend to change the process by themselves is very important for routine processes and extremely important for nonroutine processes. For this reason, one might have expected a higher importance for routine processes due to their structured and predefined nature. Thus, we think that here is a need for further examination in the future. The reason that process participants are often interrupted at work is important for routine and nonroutine processes. We think that this finding is reasonable because interruptions hinder the efficiency of routine processes and the creativity of nonroutine processes. Finally, process participants who do not communicate with one another or with the process owner if needed are very important for routine and nonroutine processes. Though acknowledging that a lack of communication may cause deviant behavior in either process type, one might have expected a higher importance for nonroutine processes, based on the characteristics of nonroutine processes and the higher importance of process 
owners for nonroutine processes (see category 'governance and strategic alignment').

The 'resources' category includes three reasons that focus on the use of material and equipment during process execution. The reason that resources tend to be temporarily or systematically unavailable is extremely important for routine processes and very important for nonroutine processes. In our opinion, this is plausible as unavailable resources may cause substantial idle time, a circumstance that destroys the pace and precision of routine processes. In contrast, nonroutine processes are not as streamlined as routine processes. In addition, according to the definition of nonroutine processes, the unavailability of resources is a key characteristic. Operational work is regularly interrupted by planning and coordination activities such that idle times have less impact. Further, the reasons that a process competes with other processes for scarce resources, and that resources do not scale with varying workload, are very important for routine and nonroutine processes. We think that these results are reasonable as routine and nonroutine processes may suffer from substantial demand volatility.

In the 'governance and strategic alignment' category, we found that all four reasons are differently important for routine and nonroutine processes. The reason that a process has no defined process owner is very important for routine and extremely important for nonroutine processes. In our opinion, this makes sense as the unpredictability of nonroutine processes requires process owners who strongly coordinate process participants and stakeholders (Hammer and Stanton 1999). The reason that the process owner is equipped with insufficient authority is a special case. It is the only reason where the median is equal for routine and nonroutine processes, but the modus and the statistics point to different importance. Thus, we treat this reason as extremely important for nonroutine processes, but also recommend further investigation. This finding complies with the previous reason, supporting that it is crucial for nonroutine processes to not only define a process owner, but also to equip this role with sufficient authority and decision rights. Whereas the process owner is a specific role, our results indicate that, in general, missing or ambiguously specified roles and responsibilities are extremely important for routine processes and very important for nonroutine processes. We think that this is reasonable as the pace and precision of routine processes require clearly defined and specialized roles, whereas the unpredictability of nonroutine processes calls for more flexible job profiles. Finally, the reason that stakeholders have unrealistic expectations regarding process performance is important for routine processes and very important for nonroutine processes. This difference is backed by the modi, but not by the test statistics such that we cannot take it as fully valid. However, we think it is reasonable as the outcome of nonroutine processes is not clearly specified when starting a process and may be subject to substantial change during process execution. Thus, it is much more likely that process stakeholders have unrealistic expectations.

The five reasons included in the 'IT in use' category are equally important for routine and nonroutine processes. The reason that required data is scattered over multiple sources is very important for routine and nonroutine processes. The same holds for the reason that relevant IT systems have unnecessarily complex user 
interfaces. This finding is in line with knowledge on technology acceptance, because user interfaces impact the perceived ease of use, which in turn influences the process participants' behavioral intention to use IT systems and the actual use (Davis 1986). The reason that relevant IT systems do not provide the required functionality is extremely important for routine and nonroutine processes. In our opinion, this is plausible as insufficient functionality of IT systems is a key reason for shadow IT and workarounds (Alter 2014; Buchwald et al. 2015). The reasons that process participants do not have access to relevant IT systems or data as well as that the process requires many and/or non-integrated IT systems to be used are very important for routine or nonroutine processes. In our opinion, this last finding is surprising as task-technology fit theory suggests that task characteristics and IT capabilities must be aligned to enable high performance (Goodhue and Thompson 1995). As routine processes strive for pace and precision, one might have expected a higher importance of non-integrated IT systems.

In sum, reasons related to process documentation, customers, knowledge and skills of process participants, resources, and IT in use were assessed as almost equally important for routine and nonroutine processes. Reasons related to the process itself, attitudes and behavior of process participants as well as governance and strategic alignment tend to show the greatest differences. For example, the deviance of routine processes is driven more strongly by inappropriate tasks and control flows, process design without consulting process participants and stakeholders, unavailable resources as well as missing and ambiguously specified roles and responsibilities. In contrast, the deviance of nonroutine processes depends to a greater extent on the inability to deal with different contexts, process participants' ignorance of how their work contributes to the overall outcome, a lack of identification with process objectives, unmotivated process participants as well as missing and powerless process owners. While, in our opinion, most findings are plausible when considering the characteristics of routine and nonroutine processes, we also encountered commonalities and differences that could not be unambiguously justified based on the data available. In line with the nature of the Delphi method, findings on the reasons' importance for causing deviance in routine and nonroutine processes should be interpreted as trend statements. They should be challenged in future research, e.g., by conducting semi-structured interviews with process managers as well as by leveraging a larger sample and confirmatory research methods such as surveys.

\section{Discussion}

\subsection{Theoretical implications}

Despite the growing interest in academia and industry, process deviance is low on theoretical insights. Against this backdrop, our study makes two contributions to the descriptive knowledge on BPM in general and process deviance in particular: first, a compilation of 33 reasons for process deviance structured along nine categories, which are grounded on the input of academic as well as industry experts and have 
been approved by these experts; second, preliminary insights into the reasons' importance for causing deviance in routine and nonroutine processes together with commonalities and differences.

Our findings extend current work on process deviance, most of which focuses on the detection (ex post view) and runtime prediction (ex nunc view) of process deviance based on process models and logs for business processes executed in automated workflow environments (Swinnen et al. 2012; Maggi et al. 2014; Nguyen et al. 2014; Delias 2017). While the value of these approaches is unquestioned, they focus on automated decision support and do not explain why processes show different behavior than intended. Existing approaches also neglect many processes from reality, namely those that are not or cannot be executed in automated workflow environments. Our findings strengthen the ex ante view on process deviance, and extend those works that already analyzed reasons for process deviance (Mertens et al. 2016b; Delias 2017). The reasons identified in our study apply to business processes in general, and only require the experience of process managers to be assessed. Finally, our findings extend research on success factors related to BPM and process reengineering projects. While Trkman (2010) proposed BPM success factors that address the fit between business processes with their business environment and IT, Al-Mashari and Zairi (1999) focused on success factors for process reengineering projects including effective communication, strong leadership, appropriate job descriptions, adequate resources, or effective IT. Bandara et al. (2005) investigated success factors specifically for process modeling initiatives. Although some success factors bear similarities with reasons and/or categories identified in our study, they are at best indirectly linked with process deviance. Nor do they focus on individual processes as unit of analysis or are operational enough to be assessed by process managers.

Our work entails the following further implications. As we already realized during the preparation of our Delphi study, process deviance must be conceptualized differently for routine and nonroutine processes to account for the properties of both process types. In general, process deviance can be specified operationally for routine processes, i.e., as non-compliance with process models. The reason is that, due to their predictable and transactional nature, most routine processes have been specified in terms of imperative process models prior to execution. Regarding nonroutine processes, the conceptualization of process deviance must account for their unpredictable and problem-solving nature. Despite recent advances in declarative process modeling, nonroutine processes remain hard to capture at design time. In case declarative models are used, the deviance of nonroutine processes can be assessed operationally, e.g., in terms of rule or constraint violations. To the best of our knowledge, however, declarative process models are hardly used in industry so far. Most importantly, the finding that process deviance needs to be conceptualized differently for routine and nonroutine processes is corroborated by our insights into the reasons' importance for causing process deviance. Accordingly, routine and nonroutine processes call for distinct management practices related to process deviance, a requirement in line with research on context-aware BPM (vom Brocke et al. 2016). 
Further, the identified reasons and categories suggest that process deviance is a complex multi-causal concept. Reasons for process deviance are not only closely associated with the process itself (e.g., included tasks, control flow, and documentation), but also with their context in terms of involved process participants, IT systems, and resources (i.e., material, equipment, employees). Further, reasons for process deviance are also associated with less operational and sometimes hardly tangible topics, known to be relevant for BPM as a corporate capability, such as governance and strategic alignment or process participants' knowledge and skills as well as their attitude and behavior (Rosemann and vom Brocke 2015). This finding pinpoints the limitations of data-driven approaches when it comes to the analysis and management of process deviance. We also found that the relationship of most reasons with process deviance has a positive polarity, whereas some reasons appeared to have an inverse U-shaped relationship. A positive polarity means: the more one agrees with a reason, the stronger the process in focus tends toward deviance. An example is the reason that process participants do not have sufficient knowledge or skills. In contrast, an inverse U-shaped means that there can be a too much and a too little. Examples are the reasons that processes deal inappropriately with different contexts or that processes include an inappropriate control flow. Finally, our results inspire research on process deviance proneness, i.e., the tendency of business processes toward deviant behavior, and context-aware BPM, i.e., the design of appropriate management practices for routine and nonroutine processes.

\subsection{Managerial implications}

Our study also offers practical implications for process managers. Analogous to the theoretical insights, our results sensitize process managers to process deviance being a complex multi-causal construct that needs to be assessed holistically. Moreover, using the identified reasons as a checklist, process managers can easily assess to which extent the processes in their area of responsibility tend toward process deviance. Despite the explorative nature of Delphi studies, it is justified to use the reasons as a checklist because the panelists agreed on them throughout multiple rounds. Using the identified reasons as a checklist offers a low-threshold assessment tool as process managers only require their own knowledge. Moreover, process managers can apply the reasons in any application domain. When assessing to which extent business processes tend toward deviance, process managers can derive custom weights for each reason based on the reasons' importance for routine and nonroutine processes. Process managers can leverage such assessment results for multiple purposes: From a stand-alone perspective, process managers can use the results for redesigning existing or creating novel business processes. From a process portfolio perspective, they can leverage the assessment results to prioritize processes for improvement purposes if they contrast the processes' tendency toward deviance against the expected impact of process deviance. Finally, our reasons make the case for not only checking for process deviance during or after process execution. Rather, process deviance should also be considered at design time and when redesigning existing business processes before it occurs. 


\subsection{Conclusion and further research}

To account for the ubiquity of and call for research on process deviance, this study identified, structured, and rated reasons for process deviance that can be assessed from a process manager's perspective without requiring process models and logs as input. To do so, we conducted a rating-type Delphi study with more than 30 experts from academia and industry. This study resulted in 33 reasons for process deviance, structured along nine categories. Our study also resulted in preliminary insights into the reasons' importance for causing deviance in routine and nonroutine processes.

Our study is beset with limitations. As with any Delphi study, our results are based on the input of a limited number of panelists. While we chose the panelists for their experience in BPM and their ability to take a managerial perspective on process deviance, we can make no formal claim about the representativeness of our study. Although we did not control for distinct industries or an experience regarding different process types, we are convinced that our Delphi panel is sufficiently diverse, because the panelists stem from multiple countries, have different academic backgrounds, and hold different positions in organizations. Although the composition and size of our Delphi panel fitted the exploratory nature of our research, the panel is comparatively small for statistical purposes. Therefore, the insights into the reasons' importance for causing deviance in routine and nonroutine processes as well as related differences and commonalities should be treated as trend statements. During the study, a few panelists shared their opinion that our panel may have included too many highly qualified panelists with a strong managerial perspective. They suggested that the study be replicated only with process participants to cover an operational perspective on process deviance. With our study aiming to identify reasons for process deviance from a process manager's perspective, we do not see an overly strong bias toward management experience within the panel. Nevertheless, we appreciate the idea of covering an operational perspective or further perspectives on process deviance in follow-up studies to complement our findings. As we strived for reasons that apply to business processes in general and can be assessed by process managers, some reasons tend to be abstract. However, this is in line with the setup of our study. As just mentioned, our reasons should be complemented by more operational reasons identified by taking other perspectives on process deviance and by domain-specific reasons. Finally, we treated the identified reasons as independent. In reality, process deviance is likely to depend on interactions among reasons, e.g., if some reasons occur simultaneously.

Both the limitations of our Delphi study and our results stimulate further research. Below, we overview the most prominent streams for future research, starting with the mitigation of limitations followed by ideas that take our results one step further.

- To address the limitation that our Delphi study focused on reasons for process deviance from a process manager's perspective, we recommend that future research covers the perspectives of other roles such as process participants, process portfolio managers, or BPM method specialists. Beyond, future research should investigate process deviance for different application domains (e.g., sales 
or production processes) and process contexts (e.g., knowledge-intensive or inter-organizational processes). These activities will contribute to a holistic understanding of reasons for process deviance, which can then be used as foundation for future studies on process deviance. Not all other perspectives on process deviance can be covered by the Delphi method. While the Delphi method may also be appropriate for process portfolio managers or BPM method specialists, the perspective of process participants may be covered most suitably through interviews, ethnographies, or observations.

- To advance our insights into the reasons' importance for causing deviance in routine and nonroutine processes and to challenge underlying causalities, we recommend applying both further exploratory research methods (e.g., interviews) and confirmatory methods (e.g., surveys). In the latter case, it is necessary to involve a larger expert sample. Such studies help verify which reasons cause process deviance and explore why some reasons are differently important for routine and nonroutine processes. Survey-based research can also reveal whether the occurrence of distinct reasons tends to entail positive or negative effects on process performance. As the reasons identified in our Delphi study only indicate that a business process may show different behavior than intended, which needs to be conceptually separated from related performance effects, such insights are still missing. In line with the exploratory nature of our study, the identified reasons for process deviance can serve as hypotheses for survey-based follow-up studies. The classification of processes into routine and nonroutine processes (or any other reasonable classifications) can be used as moderators.

- To address the limitation that the identified reasons for process deviance were treated as independent from one another, further research should explore general relationship types among reasons for process deviance as well as concrete interactions among individual reasons. Particularly for prescriptive research on process deviance, knowledge about relationship types and interactions will provide guidance when it comes to the prioritization of reasons or to the quantitative assessment of the likelihood that a distinct business process will be subject to process deviance.

- Finally, future research should build on the identified and further validated reasons for process deviance when theorizing about the deviance proneness of business processes and exploring the relationship between deviance proneness and process deviance. We believe that deviance proneness is an important, yet under-researched concept, as it takes an ex ante and managerial view on process deviance. These resulting insights should also be leveraged for design-oriented research. Potentially worthwhile design artifacts are deviance-aware process valuation, prioritization, and improvement methods as well as and decision support systems for deviance-aware process portfolio management. Regarding context-aware BPM, a potential design artifact is management practices for dealing with the identified reasons for process deviance in routine and nonroutine processes. 
Open Access This article is distributed under the terms of the Creative Commons Attribution 4.0 International License (http://creativecommons.org/licenses/by/4.0/), which permits unrestricted use, distribution, and reproduction in any medium, provided you give appropriate credit to the original author(s) and the source, provide a link to the Creative Commons license, and indicate if changes were made.

\section{References}

Al-Mashari, Majed, and Mohamed Zairi. 1999. BPR implementation process: an analysis of key success and failure factors. Business Process Management Journal 5 (1): 87-112.

Alter, Steven. 2014. Theory of workarounds. Communications of the Association for Information Systems 34: 1041-1066.

Alter, Steven. 2015a. A workaround design system for anticipating, designing, and/or preventing workarounds. In Enterprise, business-process and information systems modeling: 16th international conference, BPMDS 2015, and 20th international conference, EMMSAD 2015, held at CAiSE 2015, Stockholm, Sweden, June 8-9, 2015, proceedings, vol. 214, ed. Khaled Gaaloul, Rainer Schmidt, Selmin Nurcan, Sérgio Guerreiro, and Qin Ma, 489-498.

Alter, Steven. 2015b. Beneficial noncompliance and detrimental compliance: expected paths to unintended consequences. AMCIS, Twenty first Americas conference on information systems. Puerto Rico: AMCIS.

Andrade, Ermeson, Henrik Leopold, Han van der Aa, Steven Alter, and Hajo A. Reijers. 2016. Factors leading to business process noncompliance and its positive and negative effects: Empirical insights from a case study. 22nd Americas conference on information systems, AMCIS 2016, San Diego, CA, USA, August 11-14, 2016. San Diego, USA: Association for Information Systems (AIS).

Armistead, Colin. 1999. Knowledge management and process performance. Journal of Knowledge Management 3 (2): 143-157.

Bandara, Wasana, Guy G. Gable, and Michael Rosemann. 2005. Factors and measures of business process modelling: model building through a multiple case study. European Journal of Information Systems 14 (4): 347-360.

Becker, Jörg, Philipp Bergener, Patrick Delfmann, Mathias Eggert, and Burkhard Weiß. 2011. Supporting business process compliance in financial institutions-A model-driven approach. Wirtschaftsinformatik 75: 355-364.

Becker, Jörg, Brocke vom Jan, Marcel Heddier, and Stefan Seidel. 2015. In search of information systems (grand) challenges. Business and Information Systems Engineering 57 (6): 377-390.

Bennett, Nathan, and G.J. Lemoine. 2014. What a difference a word makes: understanding threats to performance in a VUCA world. Business Horizons 57 (3): 311-317.

Beverungen, Daniel. 2014. Exploring the interplay of the design and emergence of business processes as organizational routines. Business and Information Systems Engineering 6 (4): 191-202.

Buchwald, Arne, Nils Urbach, and Magnus Mähring. 2015. Understanding employee engagement in unofficial projects? A conceptual model based on psychological empowerment and constructive deviance. 36th international conference on information systems, Fort Worth, Texas, USA. Fort Worth: International Conference on Information Systems.

Chakraborty, A. 2013. Process improvement-a positive deviance approach. IEEE international conference on industrial engineering and engineering management (IEEM), 2013: 10-13 Dec. 2013, Bangkok, Thailand, 1117-1121. Piscataway: IEEE.

Conforti, Raffaele, Massimiliano de Leoni, Marcello La Rosa, Wil M.P. van der Aalst, and Arthur H.M. ter Hofstede. 2015. A recommendation system for predicting risks across multiple business process instances. Decision Support Systems 69: 1-19.

Dalkey, Norman, and Olaf Helmer. 1963. An experimental application of the DELPHI method to the use of experts: management science. Management Science 9 (3): 458-467.

Davis, Fred D. 1986. A technology acceptance model for empirically testing new end-user information systems: theory and results, Doctoral dissertation. Massachusetts Institute of Technology.

de Bruin, Tonia, and Michael Rosemann. 2007. Using the Delphi technique to identify BPM capability areas. ACIS 2007 Proceedings, vol. 42. Toowoomba: AIS Electronic Library (AISeL).

Delbecq, Andre L., Van de Ven, H. Andrew, and David H. Gustafson. 1975. Group techniques for program planning: a guide to nominal group and Delphi processes. Glenview: Scott, Foresman. 
Delias, Pavlos. 2017. A positive deviance approach to eliminate wastes in business processes. Industrial Management and Data Systems 117 (7): 1323-1339.

Deming, William Edwards. 1994. Out of the crisis: quality, productivity and competitive position, vol. 19. Cambridge: Cambridge University Press. (printing).

Depaire, Benoît, Jo Swinnen, Mieke Jans, and Koen Vanhoof. 2013. A process deviation analysis framework. In Business process management workshops: BPM 2012 international workshops, Tallinn, Estonia, September 3, 2012, ed. Marcello Rosa and Pnina Soffer, 701-706. Heidelberg: Springer.

di Ciccio, Claudio, Fabrizio M. Maggi, Marco Montali, and Jan Mendling. 2017. Resolving inconsistencies and redundancies in declarative process models. Information Systems 64: 425-446.

Dumas, Marlon, Marcello La Rosa, Jan Mendling, and Hajo A. Reijers. 2018. Fundamentals of business process management, 2nd ed. Heidelberg: Springer.

Dumas, Marlon, and Fabrizio M. Maggi. 2015. Enabling process innovation via deviance mining and predictive monitoring. In BPM-driving innovation in a digital world, ed. Jan vom Brocke and Theresa Schmiedel, 145-154. Cham: Springer.

Eder, Johann, and Walter Liebhart. 1998. Contributions to exception handling in workflow systems. In Proceedings of the sixth international conference on extending database technology: workshop on workflow management systems, ed. O. Bukhres, J. Eder, and S. Salza, 3-10. Valencia: Workshop on Workflow Management Systems.

Ferneley, Elaine H., and Polly Sobreperez. 2006. Resist, comply or workaround? An examination of different facets of user engagement with information systems. European Journal of Information Systems 15 (4): 345-356.

Ghattas, Johny, Pnina Soffer, and Mor Peleg. 2014. Improving business process decision making based on past experience. Decision Support Systems 59: 93-107.

Gimpel, Henner, Sabiölla Hosseini, Rocco Huber, Laura Probst, Maximilian Röglinger, and Ulrich Faisst. 2018. Structuring digital transformation: a framework of action fields and its application at ZEISS. Journal of Information Technology Theory and Application 1: 31-54.

Goodhue, Dale L., and Ronald L. Thompson. 1995. Task-technology fit and individual performance. MIS Quarterly 19 (2): 213.

Hammer, Michael, and Steven Stanton. 1999. How process enterprises really work. Harvard Business Review 77: 108-120.

Harmon, Paul. 2016. The state of business process management. USA: BPTrends.

Holmes, Debbie, Peter Moody, and Diana Dine. 2011. Research methods for the biosciences, 2nd ed. Oxford: Oxford University Press.

Johnston, Robert, Graham Clark, and Michael Shulver. 2012. Service operations management: improving service delivery, 4th ed. Harlow: Pearson.

Kasiri, Narges, Ramesh Sharda, and Bill Hardgrave. 2011. A balanced scorecard for item-level RFID in the retail sector: a Delphi study. European Journal of Information Systems 21 (3): 255-267.

Keeney, Sinead, Felicity Hasson, and Hugh McKenna. 2006. Consulting the oracle: ten lessons from using the Delphi technique in nursing research. Journal of Advanced Nursing 53 (2): 205-212.

Kerpedzhiev, Georgi, Martin Lehnert, and Maximilian Röglinger. 2016. The future of business process management in the future of work. In European conference on information systems 2016 proceedings, paper 81 .

Kohlbacher, Markus, and Hajo A. Reijers. 2013. The effects of process-oriented organizational design on firm performance. Business Process Management Journal 19 (2): 245-262.

Krippendorff, Klaus. 2013. Content analysis: an introduction to its methodology, 3rd ed. Los Angeles: Sage.

Lillrank, Paul. 2003. The quality of standard, routine and nonroutine processes. Organization Studies 24 (2): 215-233.

Maggi, Fabrizio M., Chiara Di Francescomarino, Marlon Dumas, and Chiara Ghidini. 2014. Predictive monitoring of business processes. In Advanced information systems engineering: 26th international conference, CAiSE 2014 Thessaloniki, Greece, June 16-20, 2014; proceedings 8484, ed. Matthias Jarke, John Mylopoulos, Christoph Quix, Colette Rolland, Yannis Manolopoulos, Haralambos Mouratidis, and Jennifer Horkoff, 457-472. Cham: Springer.

Mertens, Willem, Jan Recker, Thomas Kohlborn, and Tyge-F Kummer. 2016a. A framework for the study of positive deviance in organizations. Deviant Behavior 37 (11): 1288-1307. 
Mertens, Willem, Jan Recker, Tyge-F Kummer, Thomas Kohlborn, and Stijn Viaene. 2016b. Constructive deviance as a driver for performance in retail. Journal of Retailing and Consumer Services 30: 193-203.

Mišic, Dragan M., Miloš Stojkovic, Dragan Domazet, Miroslav Trajanovic, Miodrag Manic, and Milan Trifunovic. 2010. Exception detection in business process management systems. Journal of Scientific and Industrial Research 69: 188-193.

Mourão, Hernâni, and Pedro Antunes. 2005. A collaborative framework for unexpected exception handling. In Groupware: design, implementation, and use, ed. Hugo Fukś, Stephan Lukosch, and AnaCarolina Salgado, 168-183. Heidelberg: Springer.

Müllerleile, Thomas, Markus Orner, Michael Grimm, Volker Nissen, and Hans-Christian Reuss. 2016. Fully charged: process acceptance of different EV charging processes. SSRN Electronic Journal 4: $1-12$.

Müllerleile, Thomas, Stefan Ritter, Lucas Englisch, Volker Nissen, and Dieter W. Joenssen. 2015. The influence of process acceptance on BPM: an empirical investigation. 2015 IEEE 17th conference on business informatics, 125-132. Portugal: IEEE.

Nguyen, Hoang, Marlon Dumas, Marcello La Rosa, Fabrizio M. Maggi, and Suriadi Suriadi. 2016. Business process deviance mining: review and evaluation. arXiv preprint arXiv:1608.08252.

Nguyen, Hoang, Marlon Dumas, Marcello La Rosa, FabrizioMaria Maggi, and Suriadi Suriadi. 2014. Mining business process deviance: a quest for accuracy. In On the move to meaningful internet systems: OTM 2014 conferences, ed. Robert Meersman, Hervé Panetto, Tharam Dillon, Michele Missikoff, Lin Liu, Oscar Pastor, Alfredo Cuzzocrea, and Timos Sellis, 436-445. Heidelberg: Springer.

Okoli, Chitu, and Suzanne D. Pawlowski. 2004. The Delphi method as a research tool: an example, design considerations and applications. Information and Management 42 (1): 15-29.

Paré, Guy, Ann-Frances Cameron, Placide Poba-Nzaou, and Mathieu Templier. 2013. A systematic assessment of rigor in information systems ranking-type Delphi studies. Information and Management 50 (5): 207-217.

Recker, Jan, and Jan Mendling. 2016. The state of the art of business process management research as published in the BPM conference. Business and Information Systems Engineering 58 (1): 55-72.

Reichert, Manfred, Alena Hallerbach, and Thomas Bauer. 2015. Lifecycle management of business process variants. In Handbook on business process management 1: introduction, methods, and information systems, 2nd ed, ed. Jan vom Brocke and Michael Rosemann, 251-278. Heidelberg: Springer.

Rinderle, Stefanie, and Manfred Reichert. 2006. Data-driven process control and exception handling in process management systems. In Advanced information systems engineering, vol. 4001, ed. Eric Dubois and Klaus Pohl, 273-287. Heidelberg: Springer.

Robinson, Sandra L., and Rebecca J. Bennett. 1995. A typology of deviant workplace behaviors: a multidimensional scaling study. Academy of Management 38 (2): 555-572.

Röder, Nina, Manuel Wiesche, and Michael Schermann. 2014. A situational perspective on workarounds in IT-enabled business processes: a multiple case study. In Proceedings of the 22nd European Conference on Information Systems.

Rosemann, Michael. 2014. Proposals for future BPM research directions. In Asia Pacific business process management: second Asia Pacific conference, AP-BPM 2014, Brisbane, QLD, Australia, July 3-4, 2014; proceedings, ed. Chun Ouyang, 1-15. Cham: Springer.

Rosemann, Michael, and Jan vom Brocke. 2015. The six core elements of business process management. In Handbook on business process management 1: introduction, methods, and information systems, 2nd ed, ed. Jan vom Brocke and Michael Rosemann, 107-122. Heidelberg: Springer.

Schmidt, Roy C. 1997. Managing Delphi surveys using nonparametric statistical techniques. Decision Sciences 28 (3): 763-774.

Schmidt, Roy C., Kalle Lyytinen, Mark Keil, and Paul Cule. 2001. Identifying software project risks: an international Delphi study. Journal of Management Information Systems 17 (4): 5-36.

Schmiedel, Theresa, Jan vom Brocke, and Jan Recker. 2012. Is your organizational culture fit for business process management. BPTrends 9 (5): 1-5.

Schmiedel, Theresa, Jan vom Brocke, and Jan Recker. 2013. Which cultural values matter to business process management? Business Process Management Journal 19 (2): 292-317.

Schonenberg, Helen, Ronny Mans, Nick Russell, Nataliya Mulyar, and Wil van der Aalst. 2008. Process flexibility: a survey of contemporary approaches. In Advances in enterprise engineering I, vol. 10, 
ed. Will van der Aalst, John Mylopoulos, Norman M. Sadeh, Michael J. Shaw, Clemens Szyperski, Jan L.G. Dietz, Antonia Albani, and Joseph Barjis, 16-30. Heidelberg: Springer.

Simon, Carlio and J. Mendling. 2006. Verification of forbidden behavior in EPCs. Lecture Notes in Informatics: Modellierung 2006: 233-244.

Skinner, Richard, R.R. Nelson, Wynne W. Chin, and Lesley Land. 2015. The Delphi method research strategy in studies of information systems. Communications of the Association for Information Systems 37 (1): 31-63.

Spreitzer, Gretchen M., and Scott Sonenshein. 2004. Toward the construct definition of positive deviance. American Behavioral Scientist 47 (6): 828-847.

Swenson, Keith D. 2010. Mastering the unpredictable: how adaptive case management will revolutionize the way that knowledge workers get things done. Tampa: Meghan-Kiffer Press.

Swinnen, Jo, Benoît Depaire, Mieke J. Jans, and Koen Vanhoof. 2012. A process deviation analysis-a case study. In Business process management workshops: BPM 2011 international workshops, Clermont-Ferrand, France, August, ed. Florian Daniel, 87-98. Berlin: Springer.

Trkman, Peter. 2010. The critical success factors of business process management. International Journal of Information Management 30 (2): 125-134.

Ungan, Mustafa C. 2006. Standardization through process documentation. Business Process Management Journal 12 (2): 135-148.

van der Aalst, Wil M.P. 2013. Business process management: a comprehensive survey. ISRN Software Engineering 2013 (1): 1-37.

vom Brocke, Jan, and Michael Rosemann. 2015a. Handbook on business process management 1: introduction, methods, and information systems, 2nd ed. Heidelberg: Springer.

vom Brocke, Jan, and Michael Rosemann. 2015b. Handbook on business process management 2: strategic alignment, governance, people and culture, 2nd ed. Heidelberg: Springer.

vom Brocke, Jan, Sarah Zelt, and Theresa Schmiedel. 2016. On the role of context in business process management. International Journal of Information Management 36 (3): 486-495.

von der Gracht, Heiko A. 2012. Consensus measurement in Delphi studies. Technological Forecasting and Social Change 79 (8): 1525-1536.

Weber, Barbara, Werner Wild, Markus Lauer, and Manfred Reichert. 2006. Improving exception handling by discovering change dependencies in adaptive process management systems. In Business process management workshops: BPM 2006 international workshops, BPD, BPI, ENEI, GPWW, DPM, semantics4ws, Vienna, Austria, September 4-7, 2006; proceedings, ed. Johann Eder and Schahram Dustdar, 93-104. Berlin: Springer.

Weidlich, Matthias, Artem Polyvyanyy, Nirmit Desai, and Jan Mendling. 2010. Process compliance measurement based on behavioural profiles. In Advanced information systems engineering, ed. Barbara Pernici, 499-514. Heidelberg: Springer.

Weidlich, Matthias, Artem Polyvyanyy, Nirmit Desai, Jan Mendling, and Mathias Weske. 2011. Process compliance analysis based on behavioural profiles. Information Systems 36 (7): 1009-1025.

Publisher's note Springer Nature remains neutral with regard to jurisdictional claims in published maps and institutional affiliations. 